EDITORIAL

\title{
Short term outcome of thoracic endovascular aortic repair in patients with thoracic aortic diseases
}

\author{
Hamdy Soliman ${ }^{\text {a }}$, Mohammed N. El-Ganainy ${ }^{\mathrm{a}, *}$, Reham M. Darweesh ${ }^{\mathrm{b}}$, Sameh Bakhoum ${ }^{\mathrm{b}}$, \\ Mohammed Abdel-Ghany ${ }^{\mathrm{b}}$ \\ ${ }^{a}$ National Heart Institute, Cairo, Egypt \\ ${ }^{\mathrm{b}}$ Cardiovascular Medicine Department, Cairo University, Egypt
}

\section{A R T I C L E I N F O}

\section{Article history:}

Received 14 November 2017

Accepted 5 February 2018

Available online 27 February 2018

\section{Keywords:}

TEVAR

Thoracic aortic diseases

Aortic aneurysm

\begin{abstract}
A B S T R A C T
Aim and background: Open surgical repair for thoracic aortic diseases is associated with a high perioperative mortality and morbidity. Most of type B aortic dissections are uncomplicated and are medically treated which carries a high mortality rate. Thoracic endovascular aortic repair is the first-line therapy for isolated aneurysms of the descending aorta and complicated type B aortic dissection. The aim of this study is to test the safety of early thoracic endovascular aortic repair in patients with uncomplicated type $B$ aortic dissection and patients with thoracic aortic aneurysms.

Methods: A total of 30 patients ( 24 men and 6 females; mean age $59 \pm 8$ years) with uncomplicated type $B$ aortic dissection and descending thoracic aortic aneurysm who underwent endovascular aortic repair in National Heart Institute and Cairo University hospitals were followed up. Clinical follow-up data was done at one, three and twelve months thereafter. Clinical follow-up events included death, neurological deficits, symptoms of chronic mal-perfusion syndrome and secondary intervention. Multi-slice computed tomography was performed at three and six months after intervention.

Results: Of the 30 patients, 24 patients had aortic dissection, and 6 patients had an aortic aneurysm. 7 patients underwent hybrid technique and the rest underwent the basic endovascular technique in whom success rate was $100 \%$. Two patients developed type I endoleak, however both improved after short term follow up. The total mortality rate was 10\% throughout the follow-up. Both death and endoleak occurred in subacute and chronic cases, while using TEVAR in acute AD and aneurysm showed no side effects. Early thoracic endovascular aortic repair showed better results and less complications.

Conclusion: Along with medical treatment, early thoracic endovascular aortic repair in uncomplicated type B aortic dissections and thoracic aortic aneurysms is associated with better outcome.

(C) 2018 Egyptian Society of Cardiology. Production and hosting by Elsevier B.V. This is an open access article under the CC BY-NC-ND license (http://creativecommons.org/licenses/by-nc-nd/4.0/).
\end{abstract}

\section{Introduction}

In addition to coronary and peripheral artery diseases, aortic diseases contribute to the wide spectrum of arterial diseases. These aortic diseases include aortic aneurysms and aortic dissection. ${ }^{1}$ The Global Burden Disease 2010 project demonstrated that the overall global death rate from aortic aneurysms and AD increased from 2.49 to 2.78 per 100,000 in habitants between 1990 and 2010, with higher rates for men. ${ }^{2}$

\footnotetext{
Peer review under responsibility of Egyptian Society of Cardiology.

* Corresponding author at: Cardiovascular Medicine Department, National Heart Institute, Cairo, Egypt.

E-mail addresses: helliwa717@gmail.com (H. Soliman), mohammednabil_eg@ hotmail.com (M.N. El-Ganainy), rdrehame@gmail.com (R.M. Darweesh), samehba khoum@live.com (S. Bakhoum), dr.elghanymm@gmail.com (M. Abdel-Ghany).
}

A thoracic aortic aneurysm, is abnormal bulge in a weakened wall of the aorta in the chest area and can cause a variety of symptoms and often life-threatening complications. Due to the serious risks it presents, timely diagnosis and treatment of a thoracic aneurysms are critical. The standard surgical treatment for thoracic aortic aneurysms is open-chest aneurysm repair, but surgeons are now able to treat many thoracic and thoracoabdominal aneurysms with a minimally invasive procedure called an endovascular stent graft. $^{3}$

Aortic dissection is a potentially life-threatening condition that occurs when a tear is formed in the wall of the aorta. Stanford type B or DeBakey III aortic dissection originates in the descending thoracic aorta without retrograde extension into the ascending aorta. Type B aortic dissection may be classified as uncomplicated or complicated. Approximately $25 \%$ of patients presenting with type $\mathrm{B}$ aortic dissection are complicated at admission by malperfusion 
syndrome or hemodynamic instability, resulting in a high risk of early death if untreated. ${ }^{4}$

An acute aortic dissection ( $<2$ weeks) is associated with high morbidity and mortality rates (highest mortality in the first 7 days). ${ }^{5}$ Because of the high mortality rates associated with surgery, stable patients with uncomplicated type B dissection usually receive non operative treatment. $70 \%$ of type $B$ aortic dissections are uncomplicated and are medically treated only which carries a $50 \% 5$-year mortality rate. ${ }^{6,7}$

Patients with complicated type B aortic dissection secondary to aortic rupture, intractable pain, and/or end-organ ischemia because of aortic branch vessel involvement require intervention, but OSR is associated with high mortality rates. Such patients have increasingly been undergoing endovascular treatment, with encouraging results. ${ }^{8}$ The advent of endovascular repair of the thoracic aorta [TEVAR] has altered the management algorithm for pathologies that affect the aortic arch and descending thoracic aorta. In recent years, the number of thoracic endovascular procedures has risen. ${ }^{9}$

The increased use of TEVAR has been driven by the early morbidity and mortality advantage reported when endovascular therapy is compared with open surgical treatment of the thoracic aorta. ${ }^{10}$ TEVAR is now considered the first-line therapy for isolated aneurysms of the descending thoracic aorta. ${ }^{11}$ TEVAR is recommended in treatment of complicated type B aortic dissection and should be considered in uncomplicated aortic dissection. ${ }^{12}$

The aim of this study is to test the safety of using TEVAR in treating patients with aortic aneurysm and uncomplicated type B aortic dissection, in early intervention, and showed the outcome results through 12 months follow up.

\section{Patients and methods}

This study included 30 patients recruited from the patients with uncomplicated thoracic type $\mathrm{B}$ aortic dissection and descending aortic aneurysm who had expected life-span longer than 1 year and underwent endovascular aortic repair in National Heart Institute and Cairo University hospitals in the period between 2014 and 2016. Patients who had dissection involving the ascending aorta, severe valvular disease, CAD need surgical intervention, history of bleeding diathesis, sepsis or active endocarditis were excluded. The Ethical approval for research was obtained from the Research Ethics Committee, Faculty of Medicine, Cairo University.

All patients were subjected to full history and physical examination.12 lead ECG, chest X-ray, full echocardiographic evaluation were performed for all patients. All patients were subjected to CT scan including of thoracic, abdominal aorta and iliac-femoral axis. The following were calculated: Diameter of the aorta at different levels - Size and morphology of the aneurysm and its relationship to the side branches - Length (typically $\geq 20 \mathrm{~mm}$ ) and diameter (typically $\leq 40 \mathrm{~mm}$ ) of the healthy proximal and distal landing zones - Site of the proximal entry tear of the dissection, its extent and the involvement of important aortic branches (e.g. left subclavian artery) - Anatomy of the coronary arteries (Fig. 1).

A team of TEVAR includes two interventional cardiologists, a cardiac surgeon and an anesthesiologist. The procedure was done under general anesthesia and mechanical ventilation through trans-femoral approach. Common femoral artery was explored surgically with insertion of 6 French sheeth, an angled catheter and guidewire were used to access the abdominal aorta, and then advanced under fluoroscopic guidance into ascending aorta. It is important to keep this guidewire in place during the entire endovascular procedure. The anesthesiologist should be forewarned about these guidewires and watch for any arrhythmias they may cause. Deployment of Aortic stents differs from one com-

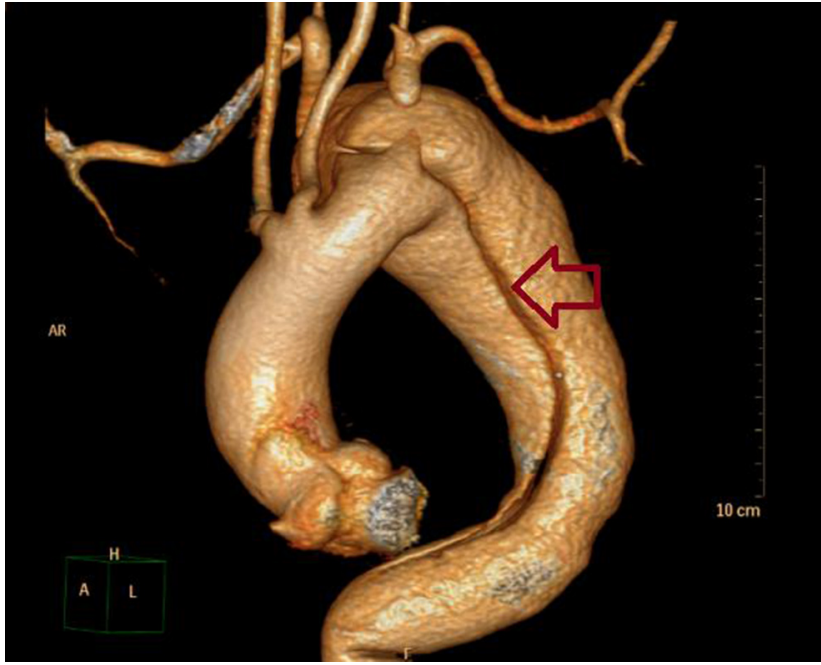

Fig. 1. Example of $A D$.

pany to another but all are self-expandable stents and we sometimes need post stenting dilatation in some cases, all the procedure was done under fluoroscopy and contrast injection for accurate positioning Fig. 2. In situations involving important aortic side branches (e.g. left subclavian artery), TEVAR was often preceded by limited surgical revascularization of these branches (the 'hybrid' approach).

Clinical follow-up events included: death from all causes, Aorta related deaths, neurological deficits (stroke or TIAs), symptoms of chronic peripheral mal perfusion syndrome (claudication, abdominal pain) and 2ry endovascular or surgical re-intervention. Multislice CT was performed at average three and six months after intervention Fig. 3.

\subsection{Primary outcome measures}

The primary endpoints were technical success during implantation, 30-day all-cause mortality and surgical conversion. The technical success of TEVAR was defined as successful deployment of the stent graft with complete coverage of the primary entry tear and no signs of type I endoleak at the end of the procedure. Technical

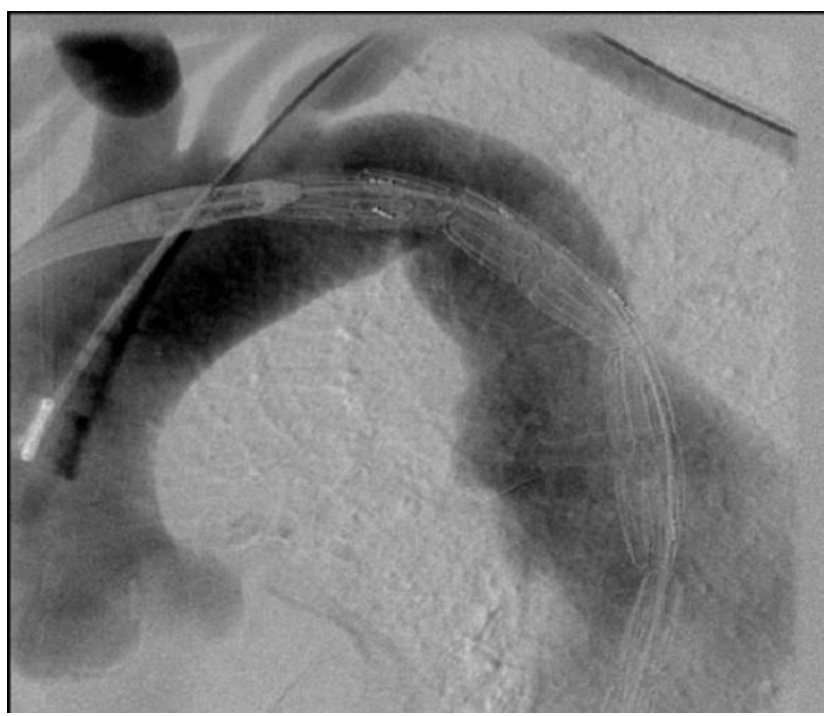

Fig. 2. Define position of stent under fluoroscopy. 


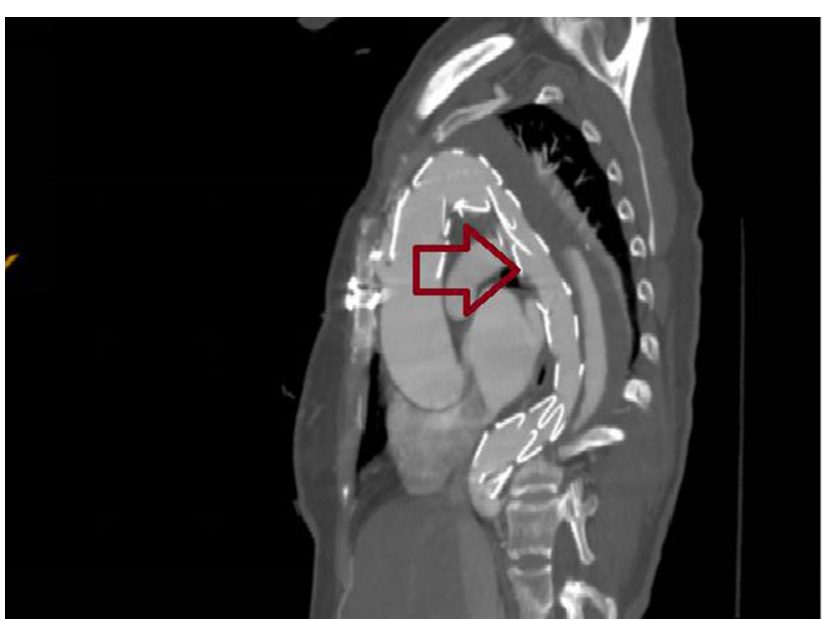

Fig. 3. Example of Post TEVAR.

success during using hybrid technique included successful open visceral bypasses.

\subsection{Secondary outcome measures}

The secondary endpoints were the procedure related complications and secondary procedures. Possible risk factors for graft related complications were also assessed. A complication was defined as any graft related complication: endoleak, endotension, migration, kinking or thrombosis of the stent graft.

\section{Results}

This prospective observational study included 30 patients. Indications of the procedure in this study were listed in Table 1.

Group I: included 24 who had uncomplicated Type B AD patients, 17 patients underwent pure TEVAR and 7 patients needed a Hybrid technique. The 24 uncomplicated Type B AD patients included 11 acute, 7 subacute and 6 chronic AD.

Group II: included 6 patients who had aortic aneurysm and underwent TEVAR.

There were male gender predominance (male $83.3 \%$ versus female $16.7 \%)$, with mean age $(55.87 \pm 9.61)$. Hypertensives were 27 patients, while diabetics were 5 patients. 18 patients had dyslipidemia and 8 patients had CAD. Smokers were 25 patients (83.3\%) (Table 2 and Fig. 4).

A postoperative stay in the intensive care unit (ICU) was needed for all patients. There was no significant difference in the ICU or overall hospital stay between cases (mean ICU stay 6.8 vs. 7.0 days, range $1-40$ days, $\mathrm{p}$ value $=0.972$ )

Table 1

Indications for treatment.

\begin{tabular}{ll}
\hline Indication & No. \\
\hline Aortic Dissection (N. 24) & \\
Acute cases & 11 \\
Sub-acute cases & 7 \\
Chronic cases & 6 \\
Hybrid technique & 7 \\
Basic Endovascular technique & 17 \\
Survival & 21 \\
Aortic Aneurysm (N. 6) & \\
Basic Endovascular technique & 6 \\
Survival & 6 \\
\hline
\end{tabular}

Table 2

Baseline characteristics.

\begin{tabular}{lll}
\hline Characteristics & Frequency & \\
\cline { 2 - 3 } & No. & $(\%)$ \\
\hline Mean age $( \pm S D)$ & $55.8(32-76)$ & \\
Gender & $( \pm 9.6)$ & \\
Male & & $(83.3)$ \\
Female & 25 & $(16.7)$ \\
Hypertensives & 5 & $(90)$ \\
Diabetics & 27 & $(16.7)$ \\
Smokers & 5 & $(83.3)$ \\
Dyslipidemic patients & 25 & $(60)$ \\
CAD patients & 18 & $(26.7)$
\end{tabular}

\section{After twelve months of follow up, Complications reported were:}

Mortality rate was (10\%). 3 patients out of the 7 patients in Group I who underwent hybrid technique died during hospital stay within the first 3 months - one case had subacute AD and others had chronic AD. Cause of death was sepsis and acute renal failure. The 3 died patients had a more complicated proximal landing zone II requiring a carotid subclavian bypass to attain proximal seal. Non acute cases of AD had mainly weakness of the aortic wall and involvement of the great branches that need more caution to deal with. 2 cases developed endoleak type I - one of them had subacute $\mathrm{AD}$ and the other case had chronic AD. Both cases improved during the first 3 months of follow up. Graft related complications as endotension, thrombosis, migration and kinking were not reported.

None of acute cases of aortic dissection nor thoracic aortic aneurysm died or developed endoleak after procedure (Fig. 5). In our series, the complications were more evident in the non acute cases of $A D$ and this may indicate that the early use of TEVAR in acute cases of dissection is associated with better outcome. Complications that occurred in the 3 died patients were attributed to their chronic underlying pathology and the using of hybrid technique (Figs. 6 and 7).

None of our patients developed stroke nor paraplegia and no TEVAR re-intervention for graft related complication as reendografting, limb graft repair, embolization, femoro-femoral bypass, conversion to open repair was done during the twelve months of follow up in all sample cases of our study.

\section{Discussion}

Regardless of the treatment method, aortic disease repair still have a considerable mortality and morbidity. Open surgical repair is applicable only to a selected group of patients and hybrid repair is still considered a major procedure. The use of endovascular treatment can minimize the surgical impact on patient with aortic disease, and help in treatment of more risky patients, with promising results. ${ }^{13}$

Patients who underwent any aortic intervention (OSR or Endovascular repair) showed a significant survival advantage over those who were medically treated only as confirmed by Durham et al. $^{14}$

Cambria et al. studied the treatment advantages of TEVAR for thoracic aortic diseases when compared with literature - based results of open surgical repair. They found that TEVAR is the preferred initial treatment for thoracic aortic catastrophes. ${ }^{15}$ TEVAR seems to have a more favorable outcome as regards aortic remodeling and the aortic specific survival rate when compared with OMT alone. ${ }^{16}$ 


\section{Baseline Characteristics}

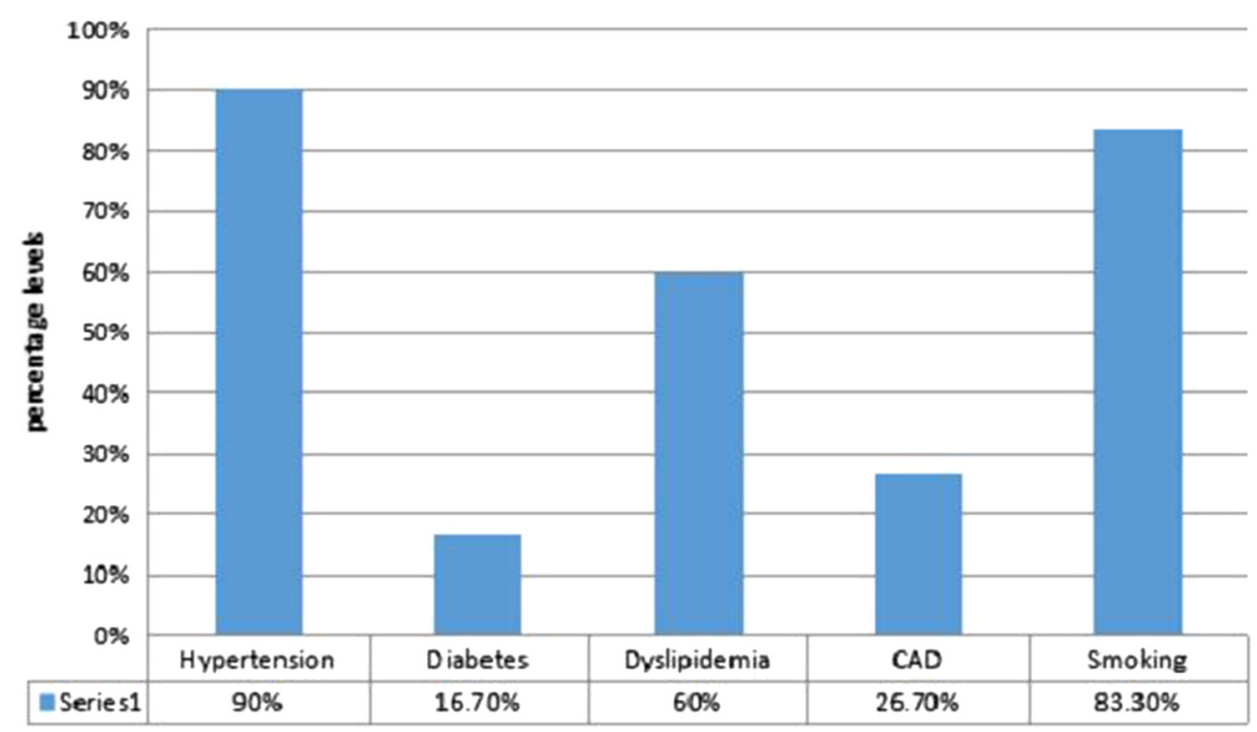

Fig. 4. Distribution of the study cases according to history of hypertension, diabetes, dyslipidemia, CAD and smoking.

Complication after 12 months

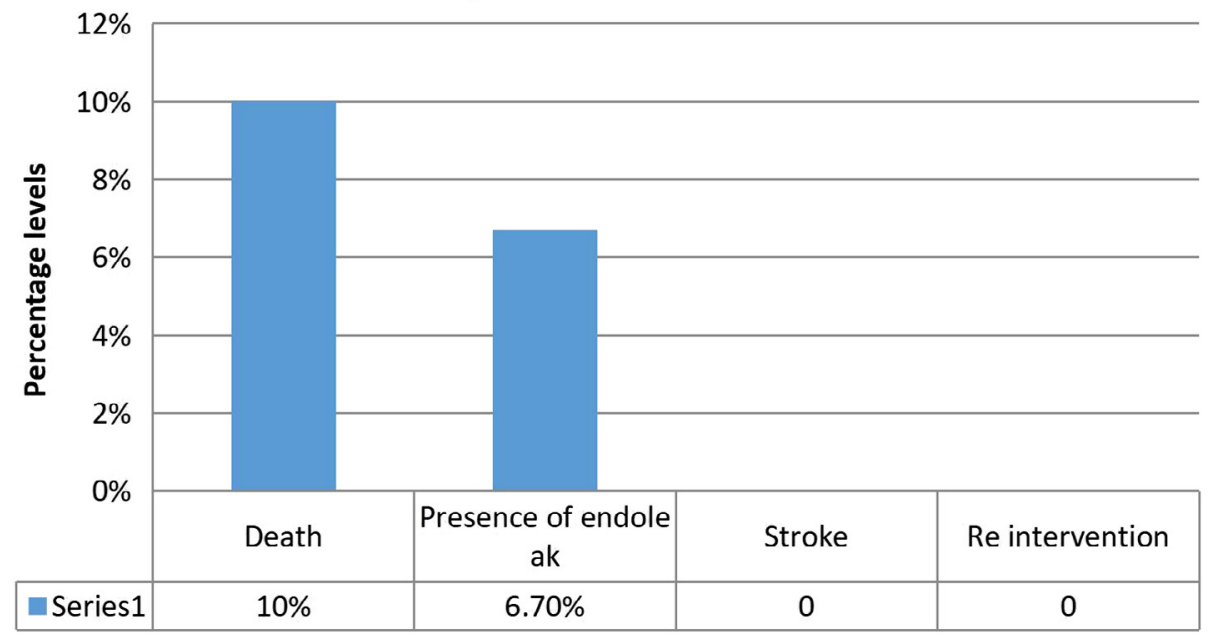

Fig. 5. Bar chart of the distribution according to complication after 12 months after TEVAR.

The result of the study of Miller et al. confirmed that TEVAR will not be widely used for the patient with uncomplicated type B aortic dissection until a prospective clinical trial shows a clear clinical advantages of TEVAR over medical management. ${ }^{17}$ So randomized controlled trials focusing on the prognostic factors of early and late complications in uncomplicated type B dissection are needed.

The results of endovascular repair in our study are promising as regards the use of TEVAR in patients with uncomplicated type $B$ aortic dissection specially those with acute presentation. Technical success was high. The 30 day operative mortality rate was $10 \%$ which attributed to their chronic pathology and the using of hybrid technique.

In this prospective observational study, early use of TEVAR in acute cases with uncomplicated Type B AD and thoracic aortic aneurysm had no side effects and the success rate was $100 \%$. Being sub-acute or chronic aortic disease are predictors of complications in Group I of patients, the earlier we used TEVAR the better outcome we get.
By comparing our study with the following studies, we found that most of these studies reached the same result of our study and the combination of early TEVAR with medical therapy seems to have a more favorable outcome e.g. Nienaber et al. who reported In INSTEAD XL Trial that TEVAR in addition to OMT is associated with improved 5-year aorta-specific survival and delayed disease progression. ${ }^{18}$ Also the result of Fattori et al. confirmed that TEVAR is associated with lower mortality over a 5 -year period than medical therapy for TBAD. ${ }^{19}$ Shah et al. in a study compared between TEVAR and medical treatment outcomes of acute uncomplicated TBAD, he also found that using TEVAR to less complicated patients could only decrease TEVAR mortality rates. ${ }^{20}$

Qin et al. also reported that TEVAR for uncomplicated type B aortic dissection in the acute setting was feasible with fewer aortic-related adverse events and a lower mortality rate compared with BMT. ${ }^{21}$ Chemelli-Steingruber et al. also reported in his study that TEVAR was a feasible treatment option in acute TBAD. ${ }^{22}$ Hughes in ADSORB trial, which evaluated TEVAR + BMT vs. BMT 


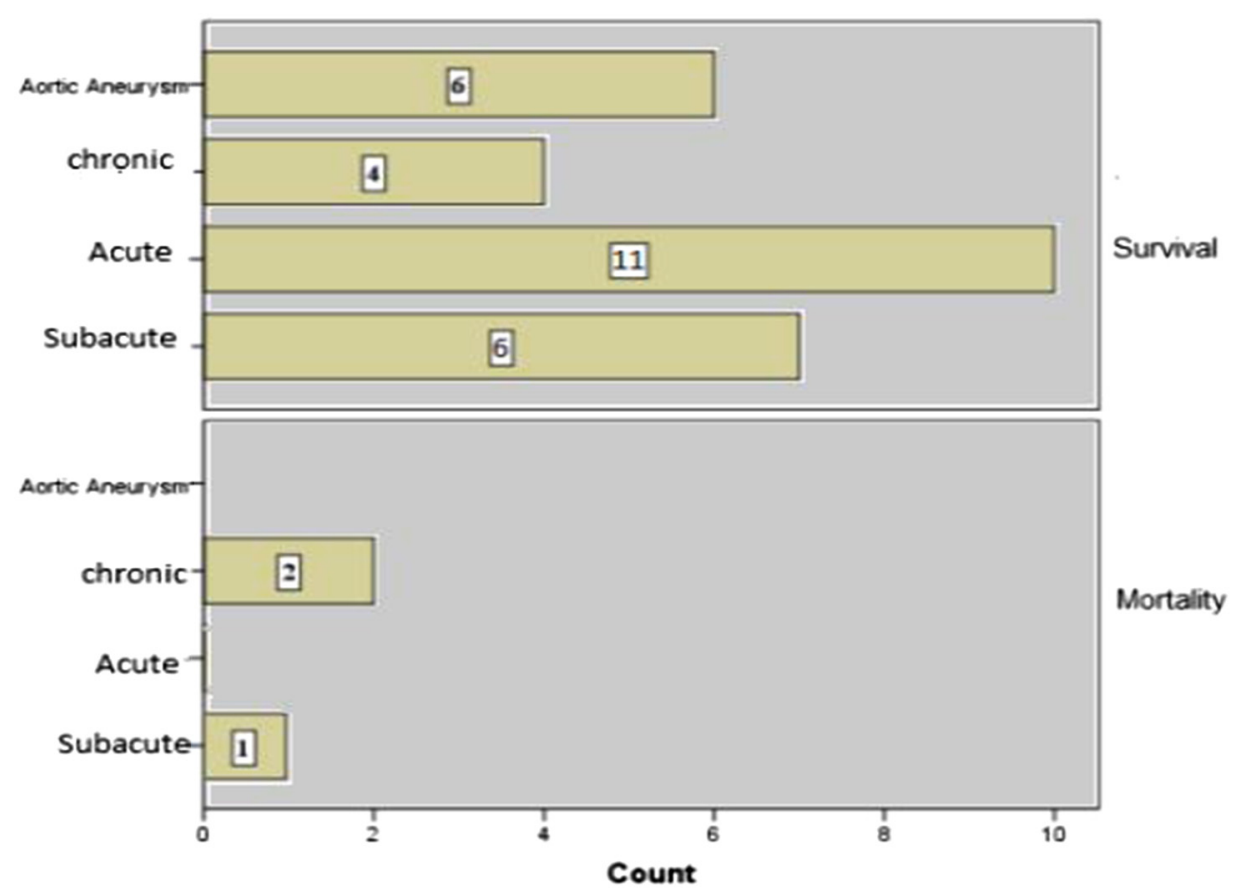

Fig. 6. Bar chart of the distribution of cases according to the mortality and pathology.

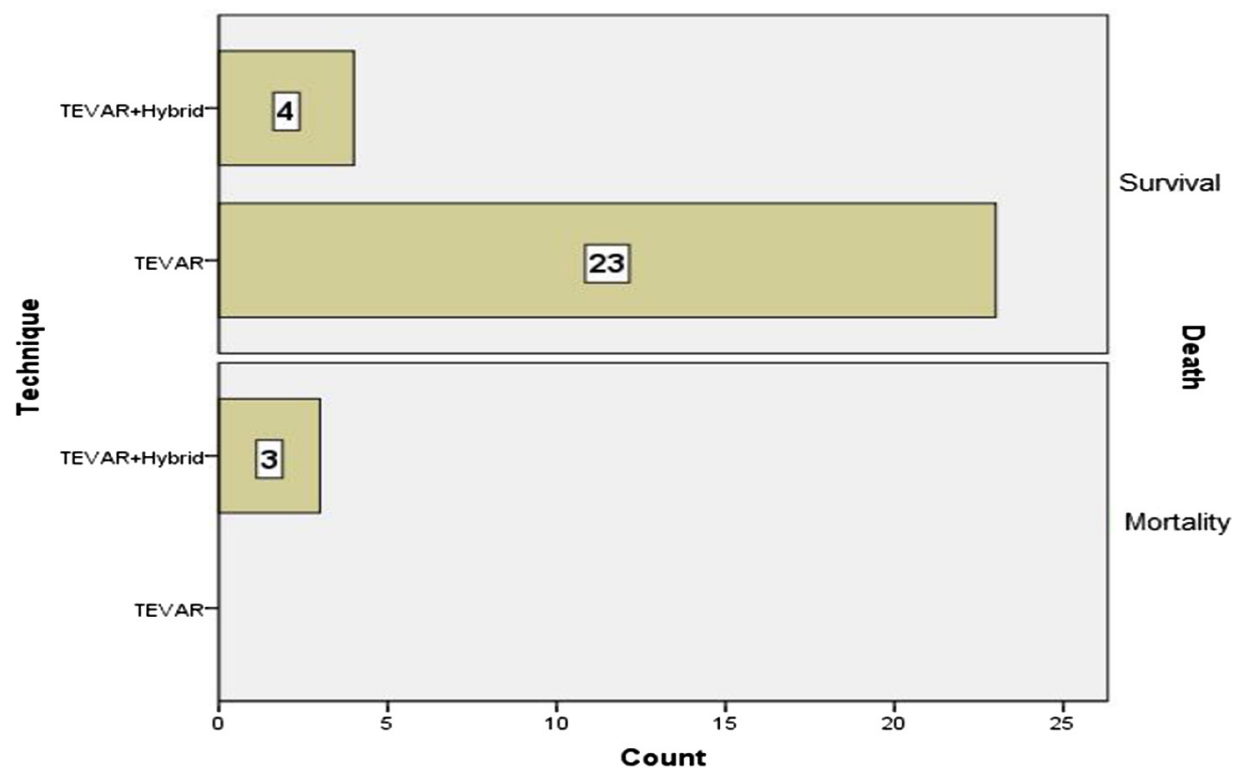

Fig. 7. Bar chart of mortality among the seven cases who underwent hybrid technique.

alone in patients with acute uncomplicated Type $B$ AD, also reported zero mortality and neurological complication rates in both groups but aortic remodeling after one year was in favor of TEVAR. ${ }^{23}$ Kamman et al. also demonstrated from (ADSORB) trial database that uncomplicated Type B AD patients were at higher risk and should receive TEVAR. ${ }^{24}$

\section{Conclusion}

According to our study and despite the small number of patient population, early thoracic endovascular aortic repair in uncomplicated type B aortic dissections and descending thoracic aortic aneurysms with medical therapy is associated with better outcome.

\section{Recommendation}

Although the ideal treatment for uncomplicated type B aortic dissection and aneurysm is still unclear, the combination of TEVAR with medical therapy seems to have a more favorable outcome as regard aortic remodeling and aorta-specific survival rate. Treating uncomplicated type B aortic dissection and aneurysm need further investigation and the outcome predicting factors of these patients may help in the identification of the best management. Until this issue is clarified, there is a need for more randomized clinical trials that will focus on the prognostic factors of early and late complications in uncomplicated aortic dissection and aneurysm and the timing of intervention. 


\section{Source of funding}

This research was governmental funded by cardiovascular medicine department in National Heart Institute and Cairo University.

\section{Conflict of interest}

The authors declare that there is no conflict of interest.

\section{References}

1. Erbel Raimund, Aboyans Victor, Boileau Catherine. The task force for the diagnosis and treatment of aortic diseases of the European Society of Cardiology (ESC). Eur Heart J. 2014;35:2873-2926. https://doi.org/10.1093/eurhearti/ ehu281.

2. Sampson UKA, Norman PE, Fowkes GR, et al.. Global and regional burden of aortic dissectionand aneurysms. Global Heart. 2014;8:171-180.

3. Abraha I, Romagnoli C, Montedori A, Cirocchi R. Thoracic stent graft versus surgery for thoracic aneurysm. Cochrane Database Syst Rev. 2013;(9):CD006796.

4. Nienaber CA. Influence and critique of the INSTEAD Trial (TEVAR versus medical treatment for uncomplicated type B aortic dissection). Semin Vasc Surg. 2011;24:167-171.

5. Cheng Z, Riga C, Chan J, et al.. Initial findings and potential applicability of computational simulation of the aorta in acute type B dissection. J Vasc Surg. 2013:57:35S-43S

6. Kato Noriyuki, Shimono Takatsugu, Hirano Tadanori, et al.. Midterm results of stent-graft repair of acute and chronic aortic dissection with descending tear: the complication-specific approach. J Thorac Cardiovasc Surg. 2001;124 (2):306-312.

7. Nienber CA, Zannetti S, Barbieri B, Kische S, Schareck W, Rehders TC. INSTEAD study collaborators: INvestigation of STEnt grafts in patients with type B Aortic Dissection: design of the INSTEAD trial - a prospective, multicenter. European randomized trial. Am Heart J. 2005;149(4):592-599.

8. Grabenwoger M, Alfonso F, Bachet J, et al.. Thoracic endovascular aortic repair (TEVAR) for the treatment of aortic diseases: a position statement from the European Association for Cardio-Thoracic Surgery (EACTS) and the European Society of Cardiology (ESC), in collaboration with the European Association of Percutaneous Cardiovascular Interventions (EAPCI). Eur J Cardiothorac Surg. 2012;42:17.

9. Scali ST, Goodney PP, Walsh DB, et al.. National trends and regional variation of open and endovascular repair of thoracic and thoracoabdominal aneurysms in contemporary practice. J Vasc Surg. 2011;53:1499-1505.
10. Jonker FH, Verhagen HJ, Lin PH, Heijman RH, Trimarchi S, Lee WA, et al.. Open surgery versus endovascular repair of ruptured thoracic aortic aneurysms. Vasc Surg. 2011;53:1210-1216.

11. Goodnes PP, Travis L, Lucas FL, Fillinger MF, Goodman DC, Cronenwett JL, et al.. Survival after open versus endovascular thoracic aortic aneurysm repair in an observational study of the medicare population. Circulation. 2011;124:2661-2669.

12. 2014 ESC Guidelines on the diagnosis and treatment of aortic diseases: Eur Heart J. http://doi.org/10.1093/eurheartj/ehu281.

13. Verhoeven ELG, Katsargyris A, Bekkema F, et al. Editor's choice ten-year experience with endovascular repair of thoracoabdominal aortic aneurysms: results from 166 consecutive patients. Eur J Vasc Endovasc Surg. 2015;49:524e531.

14. Ray HM, Durham CA, Ocazionez D, et al.. Predictors of intervention and mortality in patients with uncomplicated acute type B aortic dissection. J Vasc Surg. 2016 Dec;64(6):1560-1568.

15. Cambria RP, Crawford RS, Cho JS, et al. A multicenter clinical trial of endovascular stent graft repair of acute catastrophes of the descending thoracic aorta. J Vasc Surg. 2009; 50(6):1255-1264.e1-4.

16. Conrad MF, Crawford RS, Kwolek CJ, Brewster DC, Brady TJ, Cambria RP. Aortic remodeling after endovascular repair of acute complicated type B aortic dissection. J Vasc Surg. 2009;50(3):510-517.

17. Miller LE, Pierson LM. Discordance of aortic remodeling with clinical outcomes in patients treated with endovascular repair for uncomplicated type B aortic dissection. Interact Cardiovasc Thorac Surg. 2011 Aug;13(2):203-204.

18. Nienaber CA, Kische $S$, Rousseau $H$, et al. INSTEAD-XL trial: endovascular repair of type B aortic dissection: long term results of the randomized investigation of stent grafts in aortic dissection trial. Circ Cardiovasc Interv. 2013;6(4):407-416.

19. Fattori R, Montgomery D, Lovato L, et al. Survival after endovascular therapy in patients with type $\mathrm{b}$ aortic dissection. A report from the International Registry of Acute Aortic Dissection (IRAD). JACC:Cardiovasc Intervent. 2013;6(8).

20. Shah TR, Rockman CB, Adelman MA, Maldonado TS, Veith FJ, Mussa FF. Nationwide comparative impact of thoracic endovascular aortic repair of acute uncomplicated type B aortic dissections. Vasc Endovascular Surg. 2014;48 (3):230-233.

21. Qin Y-L, Wang F, Li T-X, et al.. Endovascular repair compared with medical management of patients with uncomplicated type B acute aortic dissection. Am Coll Cardiol. 2016;67(24):2835-2842.

22. Chemelli-Steingruber I, Chemelli A, Strasak A, et al.. Endovascular repair or medical treatment of acute type B aortic dissection? A comparison. Eur J Radiol. 2010;73(1):175-180.

23. Hughes GC. Acute Dissection Stent Grafting or Best Medical Treatment (ADSORB). J Thorac Cardiovasc Surg. 2015;149(2 Suppl):S158-S162.

24. Kamman AV, Brunkwall J, Verhoeven EL, Heijmen RH, Trimarchi S. ADSORB trialists: predictors of aortic growth in uncomplicated type B aortic dissection from the Acute Dissection Stent Grafting or Best Medical Treatment (ADSORB) database. J Vasc Surg. 2016;19. 